\title{
The Practical Realities of Alternatives to Methyl Bromide: Concluding Remarks
}

\author{
J. W. Noling
}

University of Florida, Institute of Food \& Agricultural Sciences, Citrus Research \& Education Center, 700 Experiment Station Road, Lake Alfred 33850.

Accepted for publication 23 July 2002.

Methyl bromide is extensively used for soilborne pest and disease management in many high value crops grown within the United States and abroad. The extent to which it is used and the predicted losses in crop yield when it is not, is testimonial to its importance as a soil pest management tool in commercial agriculture $(7,12)$. In 1991, methyl bromide was detected in significant concentration within the earth's stratosphere. In subsequent studies, it was shown to catalyze the destruction of ozone, and determined to be a significant contributor to stratospheric ozone depletion, thinning, and the creation of an ozone hole over Antarctica (14). Based on its estimated ozone depleting potential in 1993 (ODP = 0.7 ), methyl bromide was added to the class 1 category of ozone depleting substances, and with that, to the enforcement of the Montreal protocol phase out schedule. Since the establishment of methyl bromide as a class I ozone depleting compound in 1993, major scientific assessments of methyl bromide and stratospheric impact have been conducted in 1994 and 1998. Based on comparison of these consecutive reports, it would appear that the original ODP of methyl bromide was overestimated. Nevertheless, the most recent findings, although less severe, are not expected to alter the current phase out schedule (4). Methyl bromide is still considered an important ozone depleting substance, whether natural and or anthropogenic in source, and will be phased out of production and ultimately from use as mandated by the U.S. Clean Air Act of 1990 and globally by consensus decision of the Signatory Parties to the United Nations Environment Program Montreal Protocol Agreement.

Mandated by an incremental phase out schedule, developed countries, such as the United States, have already reduced methyl bromide use from a 1991 baseline level by $25 \%$ in 1999 and $50 \%$ in 2001. We are further scheduled to reduce use of methyl bromide by $70 \%$ in 2003 , with a complete phase out in the United States effective 1 January 2005. The real impact of the methyl bromide phase out in the United States will be expressed long before 2005 arrives, however. For example, methyl bromide production and availability will be reduced yet another $20 \%$ for a total of $70 \%$ from 1991 baseline levels on 1 January 2003. With this action, methyl bromide market price will increase yet again, as it did in 1999 and 2001, with increased demand for methyl bromide in reduced supply. After the 2001 reduction, some growers were not able to acquire sufficient quantity of methyl bromide to satisfy their previous need. As a result, there is a practical sense of urgency to identify, evaluate, and implement economically viable

Corresponding author: J. W. Noling: E-mail address: jwn@mail.ifas.ufl.edu

Publication no. P-2002-1021-080

(C) 2002 The American Phytopathological Society alternatives as quickly as possible, particularly given the few cropping seasons remaining before the next interim reduction of 2003 occurs, and the lag period typically required for technology transfer activities.

In recent years, there has been a considerable amount of scientific and political debate regarding what constitutes a technically available and economically viable alternative to methyl bromide (8). The present discussion extends beyond description of the pursuit of new scientific discovery and advancements being made in the biological and pest management sciences. It is an individual's assessment, based on general overview of collective thought. In essence, a reality check of how various alternatives, if implemented today, match up or equate to the crop yield and pest control efficacy of methyl bromide. In the practical sense and view of the grower, it is an attempt to characterize the readiness of various alternatives, either alone or in combination, to replace methyl bromide to maintain agricultural profitability and market competitiveness. It is an attempt to discuss the extent to which these alternatives address the practical needs of agricultural producers. It is personally understood, and at the same time recognized as unavoidable, the possible disagreement of some readers with the personal views expressed herein.

\section{ALTERNATIVE RESEARCH EFFORTS}

Chemical research. In recent years, many different meetings, symposia, and research conferences have been convened to summarize and discuss the broad categories of ongoing methyl bromide replacement research. Previous pesticide cancellations of critical chemicals (EDB and DBCP) were preceded by the same scientific scrutiny and negative economic forecasts as that of methyl bromide (6). Preceding the pending loss of these former chemicals, the corporate and scientific communities quickly mobilized and marshaled forces to study and address alternative pest management replacements. This has generally translated into development and use of another federally registered alternative fumigant. The present situation and course of action is not totally unlike those lost pesticides of the past. There are, however, fewer fumigant products available today as there once were, which enforces, like in the past, a comprehensive examination of the remaining fumigant compounds.

Included in the current list of fumigant compounds under investigation are chloropicrin, 1,3-dichloropropene (1,3-D), metham sodium, and other methyl isothiocyanate (MITC) generators, carbon disulfide, propylene oxide, methyl iodide, and propargyl bromide $(5,9)$. Most of the recent field research trials have focused on performance evaluations, and an examination of methods to overcome the shortcomings and constraints posed by use of 
these older fumigant compounds (6). For example, present day alternative fumigant research efforts have repeatedly demonstrated that two or more chemicals will be required to achieve pest control efficacy and crop yield response of methyl bromide. This occurs because these alternative fumigants are more target pestspecific and considerably less broad spectrum in pest control activity than methyl bromide. For example, chloropicrin is an excellent fungicide but generally lacks activity against nematodes and weeds, and additional measures will be needed to provide a full spectrum of alternative systems (10). Neither chloropicrin nor 1,3-D are as effective as methyl bromide for weed control. Thus, a stand-alone herbicide application would be required for adequate weed control. With the possible exception of methyl iodide or propargyl bromide, there is no single chemical, drop-in, replacement for methyl bromide. It is also very clear that some combination of fumigants, herbicides, and or other alternative tactics will have to be developed and evaluated over time to achieve the same broad-spectrum pest control and yield obtained with methyl bromide. Unfortunately, many of these fumigant compounds have current regulatory restrictions, which will prevent their widespread adoption and use. These restrictions can include the need for personal protective equipment at the time of application, and in some cases, large buffer zones restricting fumigant applications in proximity to occupied dwellings or structures $(10,11)$. There is also no assurance that future regulatory actions may not compromise availability or prevent use of these replacement chemical compounds. We should be reminded that history has a tendency to repeat itself.

Proactive research programs have been initiated to consider the various ways in which to mitigate future regulatory problems via changes in fumigant application and containment technologies. For example, use of virtually impermeable plastic mulches or films (VIF) has proved to be a simple and effective strategy to reduce soil emissions of not only methyl bromide but of other fumigant gases as well $(6,11)$. Using VIF, fumigant use rates can be substantially reduced without serious consequence to pest control efficacy or crop yield response. Growers may even be able to distribute what methyl bromide they can acquire to adequately treat their existing acreage without incurring significant loss of pest control or yield or to have to completely rely on alternative tactics at this time. This is not likely to occur without problems, however. VIF mulches have suffered from high cost and from other problems involving tensile strength, are slow to properly install, and from tearing during machine application in the field. Laboratory and field research is continuing to focus on ways to resolve many of these problems.

Significant advancements are also being made in the area of soil application technologies of the alternative fumigants via standard shank and drip irrigation delivery systems $(10,11)$. Regardless of the method, pest control efficacy of all the available fumigant alternatives is highly dependent upon uniform soil delivery, distribution, and uniformity of soil type and conditions within the field. Unlike methyl bromide, prevailing edaphic and climatic conditions during pre- and postfumigant application are very important in dictating treatment efficacy and crop response. For example, seasonal differences in temperature and rainfall patterns can adversely affect fumigant dissipation from soil, and thus reduce the overall value of the fumigant alternative by causing treatment inconsistency and lower average yield (10). Research to determine the optimum conditions and procedures required to maximize performance is continuing.

At the same time it would appear that uniform application, distribution, and soil conditions cannot be realistically achieved in every field. Because the alternative fumigants are generally less effective with a lower spectrum of activity than methyl bromide, they are also more variable in response. It is clear that these alternative fumigants are less consistent in response to that of methyl bromide and further testing is required to ensure that these new technologies are suitable for repeated field use. The practical reality is that some pest control and crop yield response inconsistency is unavoidable with all of the alternative fumigants currently under investigation.

Nonchemical research. Pest and crop response inconsistency is not limited exclusively to the chemical alternatives but also to nonchemical approaches (8). For example, soil solarization in many cases has not provided consistently effective control of many weeds, diseases, or of root-knot nematode (11). Soil solarization appears to work best in systems emphasizing crop rotation and other IPM practices (1). Like the alternative fumigants prevailing, soil and climatic conditions significantly influence the performance of soil solarization. Broccoli, cauliflower, canola, and other Brassica spp. have been evaluated as rotation crops for their biofumigant suppressive effects on soil pest density (13). In many, if not most cases, biofumigation was intermediate to that of methyl bromide and nontreated control in terms of pest suppression and crop yield enhancement. Scientific advancements have also been made in our understanding of soil microbial community structure, associated variability, and their importance in regulating crop growth and pest suppressive effects. In general, these approaches have included a characterization of rhizosphere and nonrhizosphere ecology and changes in microbial population structure with time (2). Only a relatively small number of soil organisms have been critically examined, and in some cases, the pathogens involved in the disease complex affecting a particular crop still are not known. It has also been repeatedly shown that different isolates can affect plant growth both positively or negatively depending on the particular environmental setting. Our understanding of these complex biotic systems has not evolved to the point of their development as uncoupled replacements to methyl bromide.

The continued viability (productivity and consistency) of agricultural production systems is directly related to its weakest IPM link (3). For example, there is ample evidence to suggest that some soilborne diseases cannot be adequately managed without pesticides because many of the nonchemical approaches are not sufficiently broad spectrum and simple suppression of pest densities unacceptable (7). To compound the problem, few real decision aids for IPM (monitoring techniques, economic thresholds, and crop rescue technologies, etc.) are not available for grower use. Some diseases cannot be adequately managed without simultaneous consideration and use of nematode management. Given the wide host range of some nematode genera, most notably Meloidogyne, it is also becoming increasingly clear that some nematodes cannot be adequately managed without simultaneous consideration of weed management. The interdependency and complexity of the soilborne pest and disease problems typically encountered in agriculture demands solutions involving a truly integrated pest and crop management approach $(1,3)$. The change from methyl bromide to another system is expected to create changes in pest species diversity and density, and even with the emergence of different pest problems over time.

Multitactic interactions. It is also becoming increasingly clear that even with multitactic approaches, unexpected outcomes and incompatibilities between pest and crop management strategies can occur (3). For example, there is some evidence to suggest that the coupling of organic amendments with plant resistance may in fact accelerate selection pressures for resistant breaking pest biotypes due to plant growth promoting effects. Coupling the use of organic amendments with soil fumigation may in fact reduce the diffusivity of the fumigant in soil, thereby reduce efficacy, and promote the need for even higher fumigation rates to achieve satisfactory soilborne pest and disease control. There is also preliminary information to show that the half-life and efficacy of some herbicides are prolonged due to the elimination of organisms responsible for microbial degradation of the herbicide. In pasteurized soils, higher rates of some herbicides are likely to be required 
to kill weeds than in nonpasteurized soil due to the removal of synergistic organisms responsible for root decay. These are but a few of many possible interactions that have arisen between methyl bromide and replacement tactics and must be addressed.

Global transferability. Another important consideration associated with alternative research efforts is the extent to which proposed alternatives can be globally transferred to geographic regions in which significant biotic and abiotic differences exist between locations (8). For example, the success to which biocontrol organisms or other microbial inoculants can successfully be introduced and maintained in the desert environments of California are not likely to be successfully transferred to subtropical Florida field locations, which are periodically subjected to flooding and anaerobic conditions. At least some of the proposed tactics to replace methyl bromide cannot be implemented and transferred everywhere, enforcing independent development and evaluation of alternatives in multiple locations around the globe.

Response inconsistency. From a grower perspective, the major challenge is to resolve problems of pest control and yield response inconsistency with the majority of the proposed chemical and nonchemical alternatives (12). The principal contributing factors to the observed pest and crop response inconsistency involve various chemical, physical, biological, and environmental factors (10, 11). Growers and their employees can be responsible for contributing to significant response variability due to inappropriate land preparation or suboptimal application procedures, particularly when complex, rather than simple, pest management systems must be implemented by subordinate field coworkers. Based on general overview of alternative research trials, the current practical reality is that some pest control and yield response inconsistency is probably unavoidable. Unfortunately, some crop or commodity organizations have proposed that even minor changes in field unit productivity and consistency will significantly impact the survival of some methyl bromide-dependent agricultural industries $(8,12)$.

General conclusions. As biologists, it is appropriate to examine the practical realities and potential outcomes of the alternative strategies we research. A very diverse approach has been taken to identify and evaluate potential replacement strategies for soil fumigant use of methyl bromide. These have included various chemical and nonchemical tactics, including a number of combinations. There has also been a considerable amount of ongoing discovery type research, many of the breakthroughs of which will probably not occur in a time frame to be production ready by 2001 to be of much practical value. It is also clear that this research has not targeted all crops currently dependent on methyl bromide. For example, turf, forest nurseries, and broad range of ornamental and floricultural crops are prominent examples in which extensive research to identify and evaluate alternatives to methyl bromide has not been performed. It would also be dangerous to assume that identical strategies could be employed for all crops or to assume their global transferability from one crop or production region to another.

Based on the results of many, if not most, of the field research studies, it is clear that some pest control, and therefore crop yield, response inconsistency is unavoidable. There are no single tactic stand-alone replacements for methyl bromide. Simple suppression (marginal changes) of pest population density is generally not acceptable, unless coupling multiple tactics incrementally reduces disease incidence or severity to economically tolerable levels. Future efforts must focus on coupled strategies, focusing on cost effective, truly integrated pest management-based strategies. The translations of these inconsistencies into on-farm economics will ultimately determine the extent to which the IPM alternatives can or will be implemented in commercial agriculture. Cost, consis- tency, and ultimately risk drive on-farm utilization and large-scale agricultural implementation. With regard to the economics of IPM, many other complex factors and issues must be considered. For example, it is not just total crop yield per unit area and consistency, but issues of growth and or fruiting synchrony, grade, quality, packinghouse efficiency, and other production constraints such as land, labor, capital, and marketing that will drive the acceptance of alternative tactics to methyl bromide. Furthermore, if clean plant material is not available to the commercial growers for transplanting into their fruit production fields, attempts to control root diseases in these fields will be all the more difficult, if not impossible to attain. It is also prudent to recognize and appreciate that the buffering capacity of industries currently now dependent upon methyl bromide are only as absorptive as global competitive forces allow. The study of alternatives may be a mute point given general trends and predictions, and given that most breakthroughs will not occur in a time frame to be of much practical significance. In all reality, production systems will change and the degree to which proposed alternatives are adopted will depend on long-term yield consistency and quality, costs, and a matrix of other factors.

\section{LITERATURE CITED}

1. Chellemi, D. O., Olson, S. M., Mitchell, D. J., Secker, I., and McSorley, R. 1997. Adaptation of soil solarization to the integrated management of soilborne pests of tomato under humid conditions. Phytopathology 87:250-258

2. De Ceuster, T. J. J., and Hoitink, A. J. 1999. Prospects for composts and biocontrol agents as substitutes for methyl bromide in biological control of plant diseases. Compost Sci. Util. 7:6-15.

3. Duncan, L. W., and Noling, J. W. 1998. Agricultural sustainability and nematode IPM. Pages 251-287 in: Plant-Nematode Interactions. K. R. Barker, G. A. Pederson, and G. L. Windham, eds. Agronomy Society of America. Monog. Ser. Madison, WI.

4. Federal Registrar. 1993. Fed. Registrar. 58:65018-65082.

5. Hutchinson, C. M., McGiffen, M. E., Jr., Ohr, H. D., Sims, J. J., and Becker, J. O. 2000. Efficacy of methyl iodide and synergy with chloropicrin for control of fungi. Pest Manag. Sci. 56:413-418.

6. Lamberti, F., and Noling, J. W. 1999. Soil fumigation for nematode control: Present and future constraints. Page 6-14 in: Soil Solarization and Integrated Pest Management of Soilborne Pests. J. J. Stapelton, J. E. DeVay, and C. L. Elmore, eds. Food and Agricultural Organization of the United Nations. FAO Plant Prod. Prot. Ser. No. 147.

7. Noling, J. W. 1996. The role of soil fumigants in Florida agriculture. Pages 14-24 in: Fumigants: Environmental Fate, Exposure, and Analysis. J. N. Seiber, J. A. Knuteson, J. E. Woodrow, N. L. Wolfe, M. V. Yates, and S. R. Yates, eds. American Chemical Society Symposia Series 652.

8. Noling, J. W., and Becker, J. O. 1994. Viewpoint: The challenge of research and extension to define and implement alternatives to methyl bromide. J. Nematol. 26:573-586.

9. Noling, J. W., and Gilreath, J. P. 1999. Propargyl bromide, biorationals, and other fumigants for nematode control. Pages 331-333 in: Proc. Int. Res. Conf. Methyl Bromide Alternatives and Emissions Reductions.

10. Noling, J. W., and Gilreath, J. P. 2000. Methyl bromide: Progress and problems identifying alternatives. Citrus Veg. Magazine 64(3):A1-A15.

11. Noling, J. W., and Gilreath, J. P. 2001. Methyl bromide: Progress and problems identifying alternatives. Vol. II. Citrus Veg. Magazine 66(4): A1-A15.

12. Spreen, T. H., VanSickle, J. J., Moseley, A. E., Deepak, M. S., and Mathers, L. 1995. Use of methyl bromide and the economic impact of its proposed ban on the Florida fresh fruit and vegetable industry. Fla. Agric. Exp. Stn. Tech. Bull. 898.

13. Subbarao, K. V., Hubbard, J. C., and Koike, S. T. 1999. Evaluation of broccoli residue incorporation into field soil for Verticillium wilt control in cauliflower. Plant Dis. 83:124-129.

14. Watson, R. T., Albritton, D. L., Anderson, S. O., and Lee-Bapty, S. 1998. Methyl bromide: Its atmospheric science, technology and economics. Montreal Protocol Assessment Suppl., United Nations Environmental Programme on Behalf of the Contracting Parties to the Montreal Protocol. Nairobi, Kenya. 